\title{
Examination of Galectins in Phagocytosis
}

\author{
Huan-Yuan Chen ${ }^{1,2}$, I-Chun Weng ${ }^{1,2}$, Chi-Shan Li ${ }^{2}$, Lei Wan ${ }^{1,3}$, and Fu-Tong Liu ${ }^{2,4}$ \\ ${ }^{1}$ Department of Dermatology, University of California Davis, School of Medicine, Sacramento, CA, \\ USA \\ ${ }^{2}$ Institute of Biomedical Sciences, Academia Sinica, Taipei, Taiwan \\ ${ }^{3}$ School of Chinese Medicine, China Medical University, Taichung, Taiwan \\ ${ }^{4}$ Department of Dermatology, University of California Davis, School of Medicine, Research III \\ 3100D, 4645 Second Avenue, Sacramento, CA, 95817, USA
}

\section{Abstract}

Galectins, a family of $\beta$-galactoside-binding proteins, are expressed in many different phagocytic leukocytes (granulocytes, monocytes, and macrophages). A number of family members have been shown to play an important role in ingestion of particles (phagocytosis), thus contributing to clearance of damaged cells and host defense against pathogens. Here we describe procedures for analysis of the roles of galectins in phagocytosis by using galectin-3 as an example. We emphasize the function of endogenous galectin-3 as determined by comparison of phagocytosis by macrophages from galectin-3 knockout mice and wild-type mice. We focus on the role of galectin-3 in phagocytosis of pathogens and Fc $\gamma$ receptor-mediated phagocytosis of opsonized cells and particles.

\section{Keywords}

Galectin; Phagocytosis; Opsonization; Macrophage

\section{Introduction}

Phagocytosis is defined by ingestion of particles (usually larger than $0.5 \mu \mathrm{m}$ in diameter) by cells that results in invagination of the plasma membrane, followed by formation of phagosomes. Examples of particles ingested by phagocytes include dead cells (apoptotic bodies), pathogens, and inert beads (reviewed in [1]). Ingestion of dead cells results in digestion and clearance of self and unwanted cells/tissues which is critical in maintenance of tissue homeostasis. On the other hand, uptake of foreign pathogens and subsequent destruction/digestion of these microorganisms represents the protective role of phagocytosis. Phagocytosis assays can be used to identify the receptors involved in the recognition and ingestion of particles as well as elucidate the cellular mechanisms. The ingestion of particles by phagocytes can be through a nonspecific manner or via specific receptors. For example, 
$\mathrm{Fc} \gamma$ receptors on phagocytes can bind to IgG-coated particles and mediate the ingestion (opsonization).

Galectins are a $\beta$-galactoside-binding lectin family; some of the members are highly expressed by phagocytic leukocytes, such as macrophages and granulocytes. Galectin-3 was also reported to augment neutrophil phagocytosis of bacteria [2] and fungi such as Candida albicans [3]. Similarly, recombinant galectin-1 can enhance Fc $\gamma$ RI expression on human monocytes and Fc $\gamma \mathrm{RI}$-dependent phagocytosis [4]. In addition, galectin-1 can induce cell surface exposure of phosphatidylserine (PS) in neutrophils, thus facilitating phagocytosis of neutrophils by macrophages [5]. Of particular note is that the above-mentioned functions of galectins are mainly investigated with exogenously added galectins, which may not reveal the functions of endogenous galectins. Our work focuses on the roles of endogenous galectins in phagocytosis. We found that galectin-3 plays an important role in phagocytosis of opsonized red blood cells (RBC) by macrophages and it translocates to the cytosolic site of the phagosomes [6]. Galectin-9 was also found in the phagosomes as revealed by proteomic analysis [7]. Our preliminary data showed that galectin-9 is involved in phagocytosis by human monocytes (unpublished data).

This chapter describes assays to study the functions of galectin-3 in phagocytosis. Detailed procedures are provided for the $\mathrm{F} c \gamma$ receptor-mediated phagocytosis of opsonized sheep red blood cells (SRBC) and inert latex beads (Subheading 3.1). The roles of galectin-3 in phagocytosis of Listeria monocytogenes by macrophages are also described (Subheading $3.2)$.

\section{Materials}

\subsection{Fc $\gamma$ Receptor-Mediated Phagocytosis}

\subsubsection{Phagocytosis of IgG-Opsonized Sheep Red Blood Cells (SRBC)}

1. Wild-type bone marrow-derived macrophages (WT BMM) and galectin-3 knockout bone marrow-derived macrophages (Gal3KO BMM) (see ref. 6).

2. Culture medium: RPMI1640 medium with $10 \%$ fetal bovine serum (FBS), $100 \mathrm{U}$ penicillin, and $100 \mu \mathrm{g} / \mathrm{mL}$ streptomycin.

3. Sheep red blood cells.

4. Rabbit polyclonal IgG anti-SRBC antibody.

5. ACK lysing buffer: $0.15 \mathrm{M} \mathrm{NH}_{4} \mathrm{Cl}, 10 \mathrm{mM} \mathrm{KHCO}_{3}$, and $0.1 \mathrm{mM} \mathrm{Na}_{2}$ EDTA, $\mathrm{pH}$ 7.2.

6. Phosphate-buffered saline (PBS): $140 \mathrm{mM} \mathrm{NaCl}, 5 \mathrm{mM} \mathrm{KCl}, 8 \mathrm{mM} \mathrm{NaH}_{2} \mathrm{PO}_{4}$, and $2 \mathrm{mM} \mathrm{KH}_{2} \mathrm{PO}_{4}$, adjusted to $\mathrm{pH} 7.4$.

7. $2.5 \%(\mathrm{v} / \mathrm{v})$ glutaraldehyde in PBS.

8. $1 \%$ eosin solution.

9. 96-well flat-bottom tissue culture plates.

10. $15 \mathrm{~mL}$ conical plastic centrifuge tubes. 
11. 8-channel pipettor and disposable reservoirs.

12. Hemocytometer.

13. Mini-rotator.

14. Refrigerated centrifuge.

15. Inverted microscope.

16. Digital camera.

17. Incubator at $37^{\circ} \mathrm{C}$ and $5 \% \mathrm{CO}_{2}$.

\subsubsection{Phagocytosis of Inert Latex Beads}

\section{Opsonization and Fluorescence Labeling}

1. Latex beads (see Note 1).

2. Phosphate-buffered saline (PBS): $140 \mathrm{mM} \mathrm{NaCl}, 5 \mathrm{mM} \mathrm{KCl}, 8 \mathrm{mM} \mathrm{NaH}_{2} \mathrm{PO}_{4}$, and $2 \mathrm{mM} \mathrm{KH}_{2} \mathrm{PO}_{4}$, adjusted to $\mathrm{pH} 7.4$.

3. Total IgG.

4. Secondary antibody conjugated with fluorochrome.

5. DAPI or Hoechst 33342.

6. $25 \mathrm{G}$ needle.

7. Syringe.

\section{Phagocytosis}

1. Primary neutrophils, macrophages, or macrophage cell lines, such as RAW264.7 mouse macrophage cell line and THP-1 human monocytic leukemia cell line (see Note 2).

2. Latex beads prepared in Subheading "Opsonization and Fluorescence Labeling."

3. 24-well plate.

4. Incubator at $37^{\circ} \mathrm{C}$ and $5 \% \mathrm{CO}_{2}$.

5. Media: Dulbecco's Modified Eagle's Medium (DMEM) supplemented with $10 \%$ fetal bovine serum and $4.5 \mathrm{~g} / \mathrm{L}$ of glucose, L-glutamine, and antibiotics.

\section{Internal/External Particles Discrimination}

1. Media: Dulbecco's Modified Eagle's Medium (DMEM) supplemented with $10 \%$ fetal bovine serum and $4.5 \mathrm{~g} / \mathrm{L}$ of glucose, L-glutamine, and antibiotics.

2. Rhodamine labeled secondary antibody.

\footnotetext{
${ }_{1}^{1}$ The particle size used for phagocytosis ranges from 0.5 to $3 \mu \mathrm{m}$, which needs to be optimized for different experiments.

${ }^{2}$ The assays described in the section of phagocytosis of inert beads are performed with any of these phagocytic cells.
} 
3. Phosphate-buffered saline (PBS): $140 \mathrm{mM} \mathrm{NaCl}, 5 \mathrm{mM} \mathrm{KCl}, 8 \mathrm{mM} \mathrm{NaH}_{2} \mathrm{PO}_{4}$, and $2 \mathrm{mM} \mathrm{KH}_{2} \mathrm{PO}_{4}$, adjusted to $\mathrm{pH}$ 7.4.

\section{Cell Identification}

1. $4 \%$ paraformaldehyde.

2. Hoechst 33342 or DAPI.

3. Phosphate-buffered saline (PBS): $140 \mathrm{mM} \mathrm{NaCl}, 5 \mathrm{mM} \mathrm{KCl}, 8 \mathrm{mM} \mathrm{NaH}_{2} \mathrm{PO}_{4}$, and $2 \mathrm{mM} \mathrm{KH}_{2} \mathrm{PO}_{4}$, adjusted to $\mathrm{pH} 7.4$.

\section{Determination of the Phagocytic Index}

1. Imaging processing software.

2. Fluorescence microscope.

\subsection{Phagocytosis of Bacteria}

\subsubsection{Preparation and Phagocytes and Phagocytosis Assay}

1. Monocytes/macrophages: Primary monocytes/macrophages (e.g., bone marrowderived macrophages or peritoneal macrophages) and monocytic cell lines (e.g., RAW264.7 or J774A.1 cells).

2. Mid-log phase (OD600 $=0.4-0.7)$ bacterial culture (e.g., Listeria monocytogenes 10403S).

3. Complete RPMI medium: RPMI1640 supplemented with $20 \mathrm{mM}$ HEPES, $1 \times$ nonessential amino acids (NEAA), and $10 \%$ FBS.

4. Phosphate-buffered saline (PBS): $140 \mathrm{mM} \mathrm{NaCl}, 5 \mathrm{mM} \mathrm{KCl}, 8 \mathrm{mM} \mathrm{NaH}_{2} \mathrm{PO}_{4}$, and $2 \mathrm{mM} \mathrm{KH}_{2} \mathrm{PO}_{4}$, adjusted to $\mathrm{pH} 7.4$.

5. 24-well tissue culture plates containing sterilized glass cover-slips $(12 \mathrm{~mm}$ diameter).

\subsubsection{Double-Cycle Immunofluorescence Staining}

1. $5 \%$ casein blocking reagent (refer to Current Protocols in Immunology 18.13.23).

2. Antibody or antisera against the targeted bacteria (e.g., Listeria antisera, Denka Seiken).

3. Fluorochrome-conjugated secondary antibodies (e.g., Alexa Fluor 488-conjugated goat anti-rabbit IgG and Alexa Fluor 647-conjugated goat anti-rabbit IgG).

4. Washing buffer: PBS containing $1 \%$ BSA.

5. Blocking/staining buffer: PBS containing $1 \%$ BSA and $2.5 \%$ casein.

6. Fixation buffer: $4 \%$ paraformaldehyde in PBS.

7. Phosphate-buffered saline (PBS): $140 \mathrm{mM} \mathrm{NaCl}, 5 \mathrm{mM} \mathrm{KCl}, 8 \mathrm{mM} \mathrm{NaH}_{2} \mathrm{PO}_{4}$, and $2 \mathrm{mM} \mathrm{KH}_{2} \mathrm{PO}_{4}$, adjusted to $\mathrm{pH}$ 7.4. 
8. Permeabilization buffer: PBS containing $1 \%$ BSA, $2.5 \%$ casein, and $0.05 \%$ saponin.

9. Glass microscope slides.

10. Anti-fade mounting medium with DAPI (ProLong ${ }^{\circledR}$ Gold Antifade Reagent with DAPI, Molecular Probe).

11. Rhodamine-conjugated phalloidin.

12. Fluorescence microscope equipped with lasers and filter sets suitable for collecting fluorescence signals of 488, 555, and $647 \mathrm{~nm}$.

\subsection{Flow Cytometric Phagocytosis Assay}

\subsubsection{Label Bacteria with FITC}

1. $1 \mathrm{mg} / \mathrm{mL}$ FITC (fluorescein isothiocyanate) isomer 1 (Sigma) in PBS, $\mathrm{pH}$ 8.0.

2. $1 \%(\mathrm{v} / \mathrm{v})$ glutaraldehyde in PBS.

3. $1 \mathrm{M}$ glycine in PBS.

\subsubsection{Initiation of Phagocytosis and Analysis with Flow Cytometry}

1. FITC-labeled bacteria prepared in Subheading 3.2.2, step 1.

2. Adherent phagocytes in 24-well culture plates prepared in Subheading "Opsonization and Fluorescence Labeling."

3. Complete RPMI medium: RPMI 1640 supplemented with $20 \mathrm{mM}$ HEPES, $1 \times$ nonessential amino acids (NEAA), and $10 \%$ FBS.

4. Phosphate-buffered saline (PBS): $140 \mathrm{mM} \mathrm{NaCl}, 5 \mathrm{mM} \mathrm{KCl}, 8 \mathrm{mM} \mathrm{NaH}_{2} \mathrm{PO}_{4}$, and $2 \mathrm{mM} \mathrm{KH}_{2} \mathrm{PO}_{4}$, adjusted to $\mathrm{pH}$ 7.4.

5. $0.02 \%$ EDTA in PBS.

6. $1.25 \mathrm{mg} / \mathrm{mL}$ trypan blue in PBS.

7. $0.5 \%$ trypsin/EDTA or nonenzymatic cell dissociation solution such as Cell Stripper (Cellgro).

8. $1 \%$ FBS in PBS.

9. Polypropylene tube suitable for flow cytometry.

10. Flow cytometry.

\section{Methods}

\subsection{Fc $\gamma$ Receptor-Mediated Phagocytosis}

\subsubsection{Phagocytosis of IgG-Opsonized Sheep Red Blood Cells (SRBC)}

1. Place wild-type bone marrow-derived macrophages (WT BMM) and galectin-3 knockout bone marrow-derived macrophages (Gal3KO BMM) in wells of 96-well plates $\left(10^{5}\right.$ cells per well) and cultured at $37^{\circ} \mathrm{C}$ in a $\mathrm{CO}_{2}$ incubator overnight. 
2. Dilute $5 \mathrm{~mL}$ of sheep whole blood with $10 \mathrm{~mL}$ of PBS and centrifuge the cells at $800 \times g$ for $10 \mathrm{~min}$ at room temperature.

3. Remove the supernatant and buffy coat layer, and wash SRBC with $15 \mathrm{~mL}$ of PBS twice (see Notes 3 and ${ }^{4}$ ).

4. Count SRBC in a hemocytometer and adjust the cell number to $10^{8} / \mathrm{mL}$ in PBS.

5. Mix $10^{8} / \mathrm{mL}$ SRBC with rabbit polyclonal anti-SRBC antibody (subagglutination concentration, see Note 5) and incubate at room temperature for $30 \mathrm{~min}$ with gentle rotation on a mini-rotator.

6. Wash the opsonized SRBC twice with $10 \mathrm{~mL}$ of PBS and resuspend the opsonized SRBC into $10^{8} / \mathrm{mL}$ in culture medium.

7. Place the opsonized SRBC on ice for later usage (see Note 6).

8. Take out the 96-well plates containing WT BMM and Gal3KO BMM from the incubator and place the 96 -well plates on ice for $30 \mathrm{~min}$.

9. Remove the medium from the plate and add $100 \mu \mathrm{L}$ of ice-cold opsonized SRBC $\left(10^{8} / \mathrm{mL}\right)$.

10. Centrifuge the plates at $300 \times g$ for $5 \mathrm{~min}$ at $4{ }^{\circ} \mathrm{C}$ to increase the contact between SRBC and macrophages.

11. Place the plates back into the $37{ }^{\circ} \mathrm{C}$ incubator and incubate the plates for different time periods (e.g., 0, 5, 10, 20, 40, and $60 \mathrm{~min}$ ).

12. Remove the plates from the incubator and place on ice, after the indicated time periods.

13. Remove the cell medium and wash the cell monolayers with $200 \mu \mathrm{L}$ of cold PBS followed by adding $100 \mu \mathrm{L}$ of ACK lysis buffer and placing the plates on ice for 1 min to remove the SRBC not phagocytosed (see Note 7).

14. Remove the ACK lysis buffer and wash the cells with cold PBS again and fix cells by adding $100 \mu \mathrm{L}$ of fresh cold $2.5 \%$ glutaraldehyde for $15 \mathrm{~min}$ on ice.

15. After fixation, the fixed cells are washed twice with PBS and stain the cells with eosin for $5 \mathrm{~min}$ at room temperature.

16. Next, wash the cells with PBS three times and leave PBS in the wells.

17. Capture digital images under an inverted microscope.

\footnotetext{
${ }^{3}$ After centrifugation, SRBC will only form loose pellets. Be careful when removing the supernatant.

${ }^{4}$ It is better to use SRBC less than 1 week old. Aged SRBC are sticky. It is better to include a set of non-opsonized SRBC as a negative control (Fig. 1). In addition to nuclear staining, cell identification can also be accomplished by using cytosol/cytoplasm labeling. There are several different methods to label the cytosol, for example, the Qtracker kits from Life Technologies can be used to label the cell and the labeling is stable through several generations. The cells can be labeled before or after phagocytosis experiments. ${ }^{5}$ Usually the agglutination titer of the anti-SRBC antibody is provided from the commercial source. Use the concentration just below the agglutination titer.

${ }^{6}$ Opsonized SRBC can be stored at $4{ }^{\circ} \mathrm{C}$ and should be used within several hours.

${ }^{7}$ Macrophages are also destroyed by ACK lysis buffer, if the cells are exposed to the buffer for too long.
} 
18. Calculate the phagocytic index according to the following formula: Phagocytic index $=($ total number of engulfed cells/number of macrophages containing engulfed cells $) \times$ (number of macrophages containing engulfed cells/total number of counted macrophages) $\times 100$.

\subsubsection{Phagocytosis of Inert Latex Beads}

\section{Opsonization and Fluorescence Labeling (See Note 8)}

1. Resuspend $40 \mu \mathrm{L}$ of $10 \%$ suspension of latex beads in $500 \mu \mathrm{L}$ of PBS and pellet the beads by centrifugation for $30 \mathrm{~s}$ at $5,000 \times g$ in a microcentrifuge, discard the supernatant, and resuspend the beads in $500 \mu \mathrm{L}$ of fresh PBS.

2. Repeat step 1 twice to wash the beads.

3. At the third wash, resuspend the beads in $190 \mu \mathrm{L}$ of PBS and add $10 \mu \mathrm{L}$ of IgG (stock concentration: $20 \mathrm{mg} / \mathrm{mL}$ ) (see Note 9).

4. Mix gently and incubate the beads at room temperature for $60 \mathrm{~min}$.

5. Wash the mixtures three times with PBS to remove unbounded antibody and resuspend the beads in $500 \mu \mathrm{L}$ PBS.

6. Label the beads with fluorochrome for detection by fluorescence microscopy or flow cytometry by adding $5 \mu \mathrm{L}$ of fluorochrome-conjugated (e.g., FITC) secondary antibody to $500 \mu \mathrm{L}$ opsonized beads.

7. Mix gently and incubate at room temperature for $60 \mathrm{~min}$.

8. Wash the mixtures four times with PBS to remove unbounded antibody and resuspend in $500 \mu \mathrm{L}$ PBS (see Note 10).

\section{Phagocytosis}

1. Place cells in the wells of 24 -well plates at $1 \times 10^{5}$ cells/well and incubate at $37^{\circ} \mathrm{C}$, $5 \% \mathrm{CO}_{2}$ overnight.

2. Add $15 \mu \mathrm{L}$ of the labeled opsonized bead suspension to each well.

3. Shake the plate to ensure even distribution of the beads.

4. Centrifuge the plates at $300 \times g$ for 1 min to sink the beads onto the cells. Alternatively, place the plate on ice for 10 min to allow the beads to slowly settle on the cells without being internalized. Wash the cells once with media prewarmed to $37^{\circ} \mathrm{C}$ and proceed to the following step.

5. Incubate the plates at $37^{\circ} \mathrm{C}$ for 15 min to allow proper phagocytosis process. Different incubation times should be optimized for different experiments.

\footnotetext{
${ }^{8}$ The opsonization of inert latex beads is important for the phagocytes to recognize the inert beads as foreign particles. By the use of fluorochrome-conjugated antibodies that recognize the antibodies coated on the surface of the beads, we can determine the phagocytic index.

${ }^{9}$ In this protocol, we mainly focus on using IgG to coat the latex beads for Fc $\gamma \mathrm{R}$-mediated phagocytosis. One can also use complement component $\mathrm{C} 3$ bi to opsonize the beads to study complement-mediated phagocytosis.

${ }^{10}$ The opsonized beads can be stored at $4{ }^{\circ} \mathrm{C}$ for 5 days. Before performing phagocytosis, the particles should be vortexed vigorously for $5 \mathrm{~s}$ and pass through a 25-gauge needle to disrupt any text aggregates.
} 


\section{Internal/External Particles Discrimination (See Notes 11 and ${ }^{12}$ )}

1. Place the plates on ice to stop phagocytosis and wash the cells with ice-cold DMEM three times to remove unbound beads.

2. Stain the external beads with a secondary antibody labeled with a fluorochrome different from the one used in Subheading "Opsonization and Fluorescence Labeling" (e.g., Rhodamine labeled). Dilute the secondary antibody 100 -fold in cold PBS and add $200 \mu \mathrm{L}$ of diluted antibody to each well and incubate the cells on ice for $10 \mathrm{~min}$.

3. Wash the cells five times with ice-cold PBS.

\section{Cell Identification (See Note 13)}

1. Remove supernatant from cultured cells and then add $500 \mu \mathrm{L}$ of $4 \%$ paraformaldehyde in PBS into each well and incubate at room temperature for 20 min to fix the cell.

2. Stain the cell nuclei with Hoechst $33342(8 \mu \mathrm{g} / \mathrm{mL}$ ) in PBS for $10 \mathrm{~min}$ (see Note 8 (DAPI can also be used to stain nuclei).

3. Remove the excess dye by washing two times with PBS.

4. Maintain the cells in PBS until analysis by fluorescence microscopy.

\section{Determination of Phagocytic Index}

1. After phagocytosis, external particle discrimination, and cell identification, the images of macrophages are acquired by fluorescence microscopy.

2. Quantitation can be performed by using image processing software or simply counting cells one by one.

3. The efficiency can be expressed as the phagocytic index, which is defined as the number of latex beads ingested by 100 macrophages:

Phagocytic index $=($ total number of latex beads-external beads $) / 100$ macrophages.

\subsection{Phagocytosis of Bacteria}

\subsubsection{Preparation of Phagocytes and Phagocytosis Assay-Microscopic}

quantification of phagocytosis of bacteria by double-cycle immunofluorescence staining (see Note 14).

\footnotetext{
${ }^{11}$ The fluorescence can also be quenched by using trypan blue at a concentration of $250 \mu \mathrm{g} / \mathrm{mL}$ in PBS. $0.5 \mathrm{~mL}$ of trypan blue is added to each well and the mixtures are kept for 2 min at room temperature.

${ }^{12}$ When phagocytosis is complete, it is important to determine whether those particles are internalized or just adhere to cell membrane. This can be achieved by using differential labeling the external beads with different fluorochrome-labeled secondary antibody. Since the internal beads cannot be detected by the secondary antibody, the internal beads will show only the color of the first fluorochrome, while the external beads will show two different fluorescence signals.

${ }^{13}$ To quantitate phagocytosis, it is important to determine the exact number of phagocytes as well as the internal and external particles. There are several different ways to identify the cells. Here in this protocol, we use nuclear staining to identify individual cells.
} 
1. The day before phagocytosis assay, seed macrophages at a density of $1.8-2 \times 10^{5}$ cells $/ \mathrm{mL}$ in complete RPMI medium on sterile glass coverslips contained in 24well cultures plates. It is best for the cells to reach $\sim 75 \%$ confluency at the time of experiment.

2. Measure optical density at $600 \mathrm{~nm}$ (OD600) of a mid-log phase bacteria culture with a spectrophotometer and estimate the bacteria number.

3. Transfer $10^{9}$ bacteria to a new microcentrifuge tube. Sediment bacteria by centrifuging at maximum speed $(20,000 \times g)$ for $1 \mathrm{~min}$ with a table-top centrifuge.

4. Discard supernatant and resuspend with $1 \mathrm{~mL}$ sterile PBS.

5. Repeat the wash by sedimentation and resuspension in sterile PBS.

6. Dilute bacteria with prechilled complete RPMI medium to the desired density so that the multiplicity of infection (MOI) will be 5 or 10 when added to the cells.

7. Place the 24-well culture plates with macrophages on ice.

8. Aspirate culture medium and add the prepared bacteria suspension to the cells (MOI $=5$ or 10 in $1 \mathrm{~mL} /$ well).

9. Centrifuge the culture plate at $600 \times g, 4{ }^{\circ} \mathrm{C}$ for $5 \mathrm{~min}$ to facilitate bacteria adherence to cells.

10. Wash the cells gently with ice-cold medium to remove unbound bacteria.

11. Remove the culture plate from ice. Initiate phagocytosis by replacing cold medium with $1 \mathrm{~mL}$ prewarmed $\left(37^{\circ} \mathrm{C}\right)$ medium per well. Place the culture plate in $37^{\circ} \mathrm{C}$ incubator.

12. At $5,10,20,30,40,60,90$, and 120 min postinfection (or any other desired time points), stop phagocytosis by placing the culture plate back on ice.

13. Wash the cells twice with ice-cold PBS and proceed to immunofluorescence staining.

\subsubsection{Double-Cycle Immunofluorescence Staining}

1. To discriminate between extracellular bacteria that adhere to the cell surface and intracellular bacteria that have been phagocytosed, two cycles of staining will be performed on the infected cells.

2. Keep cells on ice. Add blocking buffer to the cells and incubate for $10 \mathrm{~min}$.

\footnotetext{
${ }^{14}$ This protocol describes a method to measure the ability of adhered phagocytes to ingest bacteria. Bacterial suspensions are added to cells grown on glass coverslips and centrifuged to enhance contact between the bacteria and cells. Extracellular bacteria are removed by washing (these steps are performed at $4{ }^{\circ} \mathrm{C}$ ). Phagocytosis is initiated by adding a fresh medium pre-warmed at $37^{\circ} \mathrm{C}$ and continued at $37^{\circ} \mathrm{C}$, and it is terminated at different time points by placing the cells back on ice. Bacteria are then immunostained and visualized by using a fluorescence microscope. Despite the washing step, some extracellular bacteria may remain adhered to the cell surface, and it may be difficult for the experimenter to distinguish these extracellular bacteria from those truly internalized. A doublecycle immunofluorescence staining method solves this problem by staining extracellular bacteria first, followed by cell permeabilization and a second round of staining of bacteria. Using secondary antibodies conjugated with different fluorochromes that emit different colors, one can easily discriminate intracellular single-stained bacteria from extracellular double-stained bacteria.
} 
3. Remove blocking buffer and replace with primary antibody (e.g., rabbit-antiListeria) diluted in blocking buffer. Incubate for $45 \mathrm{~min}$ on ice, and then wash for three times with washing buffer.

4. Add appropriate fluorochrome-conjugated secondary antibody (e.g., Alexa Fluor 488-conjugated goat anti-rabbit IgG) diluted in blocking buffer. Incubate for 30 min on ice followed by three washes with washing buffer.

5. Fix cells with $4 \%$ paraformaldehyde for $10 \mathrm{~min}$ on ice. Wash cells three times with washing buffer.

6. Incubate cells with permeabilization buffer for $10 \mathrm{~min}$ at room temperature (RT).

7. Remove blocking buffer and incubate cells with primary antibody (e.g., rabbit-antiListeria) diluted in blocking buffer for $45 \mathrm{~min}$ at RT. Wash three times with washing buffer.

8. Add secondary antibody conjugated with a fluorochrome different from that used in the first cycle of staining (e.g., Alexa Fluor 647-conjugated goat anti-rabbit IgG) diluted in blocking buffer. Incubate for $30 \mathrm{~min}$ at RT.

9. (Optional) Add rhodamine-conjugated phalloidin simultaneously with secondary antibody to assist identification of cell boundaries (see Note 15).

10. Wash cells for three times with washing buffer.

11. Mount samples on glass coverslides with antifade mounting medium.

12. View samples with a fluorescence microscope. Examine cells by using a $40 \times$ or greater oil-immersion objective. Count the number of single-labeled bacteria in at least 200 cells. Single-labeled bacteria represent intracellular bacteria, while double-labeled bacteria are extracellular bacteria.

13. Calculate phagocytic index according to this formula: (total number of engulfed bacteria/total number of counted macrophages) $\times$ (number of macrophages containing at least one bacterium/total number of counted macrophages $) \times 100$.

\subsection{Flow Cytometric Phagocytosis Assay (See Note 16) \\ 3.3.1 Label Bacteria with FITC}

1. Transfer $5 \times 10^{8}$ bacteria to a new microcentrifuge tube. Sediment bacteria by centrifuging at $\sim 20,000 \times g$ for $1 \mathrm{~min}$ with a table-top centrifuge. Discard supernatant and resuspend with $1 \mathrm{~mL}$ sterile PBS.

\footnotetext{
${ }^{15}$ Phalloidin selectively binds to F-actin with high affinity. Combining phalloidin staining with bacteria staining allows visualization of the cell boundaries and quantitation of the number of engulfed bacteria per cell. Some intracellular bacteria (e.g., Listeria monocytogenes and Shigella flexneri) are capable of escaping from the vacuole and polymerizing host actin to facilitate their movement inside the cells. Phalloidin also stains the actin tail of these bacteria.

${ }^{16}$ An alternative approach to analyzing bacterial phagocytosis is to allow the cells to phagocytose fluorescence-labeled bacteria and measure the fluorescence intensity of the cells by flow cytometry. Most gram-positive bacteria can be easily stained by fluorescein isothiocyanate (FITC). Following internalization of FITC-labeled bacteria by cells, extracellular FITC on the bacteria bound to the cell surface but not internalized can be quenched by trypan blue. Therefore, the fluorescence detected is from the phagocytosed FITClabeled bacteria only.
} 
2. Centrifuge again, discard supernatant, and resuspend in $1 \mathrm{~mL}$ of $1 \mathrm{mg} / \mathrm{mL}$ FITC in PBS, pH 8.0. Incubate at RT on an end-over- end rotator for $40 \mathrm{~min}$.

3. Wash labeled-bacteria for three times with PBS as in step 1. After last wash, fix bacteria in $1 \mathrm{~mL}$ of $1 \%$ glutaraldehyde. Incubate for $20 \mathrm{~min}$ at room temperature.

4. Quench free glutaraldehyde by adding $100 \mu \mathrm{L}$ of $1 \mathrm{M}$ glycine. Incubate for $10 \mathrm{~min}$ at RT.

5. Wash with PBS as in step 1 and resuspend in $500 \mu \mathrm{L}$ sterile PBS. Keep on ice.

\subsubsection{Initiation of Phagocytosis and Analysis with Flow Cytometry (See Note}

17)

1. Dilute FITC-labeled bacteria with ice-cold complete medium and add to adherent phagocytes grown in wells of a 24-well culture plate with a MOI of 10 .

2. Centrifuge the culture plate at $600 \times g, 4{ }^{\circ} \mathrm{C}$ for $5 \mathrm{~min}$ to accelerate bacteria deposition and adherence to cells.

3. Wash cells gently with ice-cold medium to remove unbound bacteria.

4. Remove the culture plate from ice. Initiate phagocytosis by replacing cold medium with $1 \mathrm{~mL}$ prewarmed $\left(37^{\circ} \mathrm{C}\right)$ medium per well. Place the culture plate in $37^{\circ} \mathrm{C}$ incubator. As a negative control, keep one sample at $4{ }^{\circ} \mathrm{C}$ the whole time so phagocytosis is not initiated.

5. At desired time points (e.g., 30 and 60 min postinfection), stop phagocytosis by adding $200 \mu \mathrm{L}$ per well of ice-cold $0.02 \%$ EDTA/PBS and move the culture plate back on ice. Wash the cells twice with ice-cold PBS.

6. Detach cells from the culture plate with $0.5 \%$ trypsin/EDTA or nonenzymatic cell dissociation buffer and collect cells in a new microcentrifuge tube. Spin down cells and resuspend in $240 \mu \mathrm{L}$ of PBS containing $1 \%$ FBS. Pipet gently repeatedly to ensure cells are dispersed into a single-cell suspension.

7. Keep cells on ice and add $60 \mu \mathrm{L}$ ( $1 / 5$ total volume) of $1.25 \mathrm{mg} / \mathrm{mL}$ trypan blue to quench extracellular FITC.

8. Transfer cells to a polypropylene tube suitable for use with flow cytometry and analyze immediately.

\section{References}

1. Flannagan RS, Jaumouille V, Grinstein S. The cell biology of phagocytosis. Annu Rev Pathol. 2012; 7:61-98. [PubMed: 21910624]

2. Farnworth SL, Henderson NC, Mackinnon AC, Atkinson KM, Wilkinson T, Dhaliwal K, Hayashi K, Simpson AJ, Rossi AG, Haslett C, Sethi T. Galectin-3 reduces the severity of pneumococcal pneumonia by augmenting neutrophil function. Am J Pathol. 2008; 172:395-405. [PubMed: 18202191]

\footnotetext{
${ }^{17}$ Compared to the control samples kept at $4{ }^{\circ} \mathrm{C}$ throughout the experiment, cells that have phagocytosed FITC-labeled bacteria show a shift in fluorescence intensity. Although this method does not reveal the absolute number of bacteria phagocytosed by each cell, the relative phagocytosis ability can be compared according to the fluorescence intensity shift.
} 
3. Linnartz B, Bodea LG, Neumann H. Microglial carbohydrate-binding receptors for neural repair. Cell Tissue Res. 2012; 349:215-227. [PubMed: 22331363]

4. Barrionuevo P, Beigier-Bompadre M, Ilarregui JM, Toscano MA, Bianco GA, Isturiz MA, Rabinovich GA. A novel function for galectin-1 at the crossroad of innate and adaptive immunity: galectin-1 regulates monocyte/macrophage physiology through a nonapoptotic ERK-dependent pathway. J Immunol. 2007; 178:436-445. [PubMed: 17182582]

5. Stowell SR, Karmakar S, Arthur CM, Ju T, Rodrigues LC, Riul TB, Dias-Baruffi M, Miner J, McEver RP, Cummings RD. Galectin-1 induces reversible phosphatidylserine exposure at the plasma membrane. Mol Biol Cell. 2009; 20:1408-1418. [PubMed: 19116313]

6. Sano H, Hsu DK, Apgar JR, Yu L, Sharma BB, Kuwabara I, Izui S, Liu FT. Critical role of galectin-3 in phagocytosis by macrophages. J Clin Invest. 2003; 112:389-397. [PubMed: 12897206]

7. Buschow SI, Lasonder E, Szklarczyk R, Oud MM, de Vries IJ, Figdor CG. Unraveling the human dendritic cell phagosome proteome by organellar enrichment ranking. J Proteomics. 2012; 75:15471562. [PubMed: 22146474] 

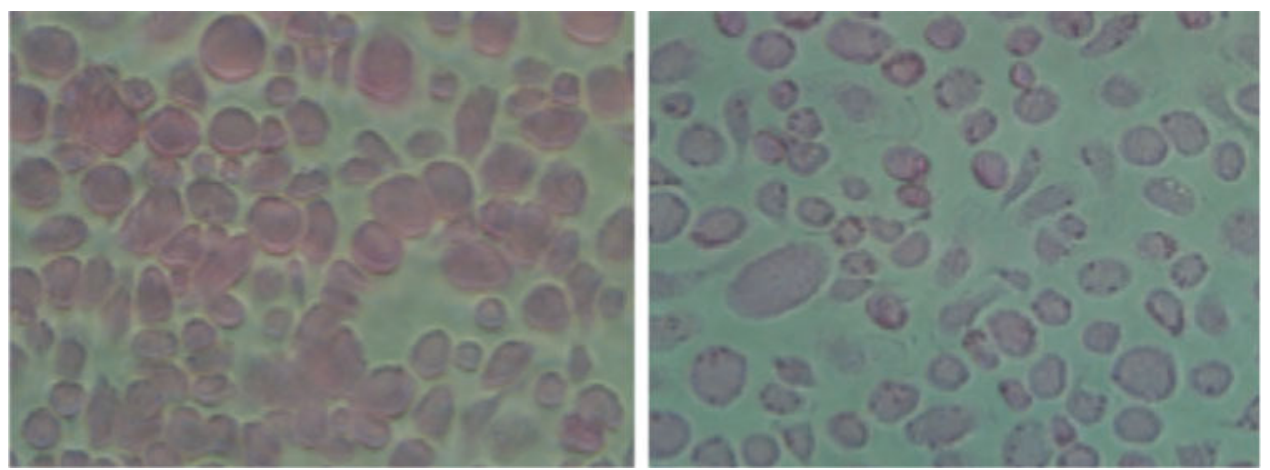

Fig. 1.

Non-opsonized SRBC (left panel) and opsonized SRBC (right panel) incubated with macrophages for $10 \mathrm{~min}$ at $37^{\circ} \mathrm{C}$ 